\title{
ENDOMETRIOSIS VESICAL. DIAGNÓSTICO Y TRATAMIENTO
}

\author{
J. CASASOLA CHAMORRO, S. GUTIÉRREZ GARCÍA*, F. FERNÁNDEZ ROJO**, \\ R. GUERREIRO GONZÁLEZ, V. DE BLAS GÓMEZ, F.J. GALLO ROLANÍA
}

\author{
Servicio de Urología. *Servicio de Ginecología. **Servicio de Anatomía Patológica. \\ Complejo Hospitalario de León.
}

Actas Urol Esp. 27 (5): 394-396, 2003

\section{RESUMEN}

"ENDOMETRIOSIS VESICAL. DIAGNÓSTICO Y TRATAMIENTO"

La endometriosis es una enfermedad ginecológica muy frecuente en la que el tejido endometrial aparece fuera de la cavidad uterina. En raras ocasiones la endometriosis afecta al tracto urinario, siendo la vejiga el órgano más frecuentemente afectado. Un retraso en su detección puede condenar a la paciente a meses de morbilidad innecesaria.

PALABRAS CLAVE: Endometriosis vesical.

\section{ABSTRACT \\ "BLADDER ENDOMETRIOSIS. DIAGNOSTIC AND TREATMENT"}

Endometriosis is a common gynecologic disease in which endometrial tissue is deposited outside the normal confines of the uterine cavity. Rarely endometriosis involves urinary tract. The bladder is the most frequent organ affected into this tract. A delay in detection can result in months or years of morbidity.

KEY WORDS: Bladder endometriosis.

$\mathrm{L}$ a endometriosis es una enfermedad que afecta al $4-15 \%$ de las mujeres en edad fértil ${ }^{1,2}$. Consiste en la aparición de tejido endometrial, glándulas o estroma, fuera de la cavidad uterina. Su localización más frecuente es la pélvica con afectación del aparato genital. Sin embargo, en un $1 \%$ de casos se afecta el tracto urinario ${ }^{3,4}$ y en un $84 \%$ de estos la vejiga, seguida del uréter con un $15 \%$, el riñón en un $4 \%$ y la uretra en $2 \% \%^{3,5,6}$. La afectación vesical puede darse de forma aislada sin que se asocien otras lesiones, siendo su detección dificultosa e importante para evitar morbilidad y limitar la evolución de la afectación con un rápido tratamiento.

\section{CASO CLÍNICO}

Paciente de 28 años sin antecedentes de interés, que es remitida por su ginecóloga con el diagnóstico de sospecha de endometriosis vesical tras el hallazgo en ecografía vaginal de lesión vesical con componente quístico. La paciente refiere desde hace dos años síndrome miccional que fue tratado repetidamente con diversos antibióticos logrando alivios parciales. En la cistoscopia se objetiva uretra normal, vejiga con buena capacidad que presenta lesión sesil en pared posterior con componente papilar en papila gruesa y quistes hemorrágicos (Fig. 1). El trígono adopta una forma de $\mathrm{V}$ invertida al ser deformado por la 


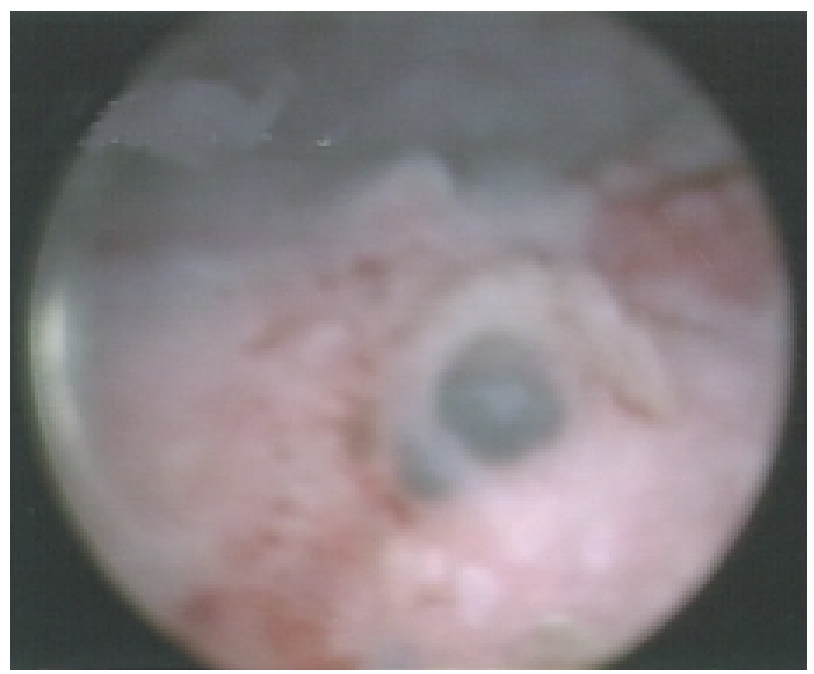

FIGURA 1. Imagen cistoscópica de un quiste endometriósico.

tracción que ejercen las lesiones, observándose una gran proximidad entre los meatos. Se procede a resección transuretral de la lesión, objetivándose la afectación del detrusor con áreas de hemorragia antigua entre sus fibras. El diagnóstico se confirma al aislarse en los tejidos resecados quistes y nidos de endometriosis (Fig. 2), con inmunohistoquímica muy positiva para receptores de estrógenos (Fig. 3) y escasamente positiva para receptores de progesterona. La paciente hizo seis meses de tratamiento con análogos de la GnRH. A los siete meses del tratamiento quirúrgico se realizó cistoscopia de control que fue normal.

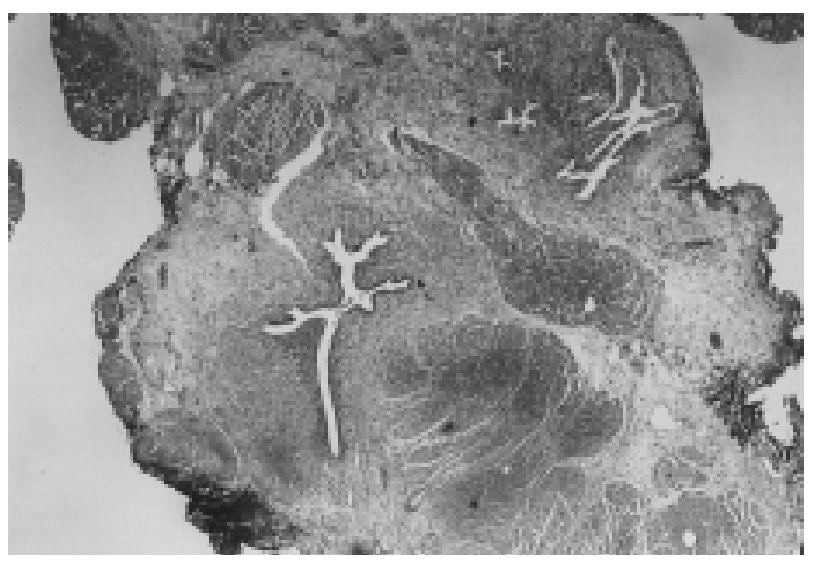

FIGURA 2. Glándulas con amplias luces plegadas rodeadas de estroma endometrial entre fasciculos de la muscular propia. H.E. $4 x$.

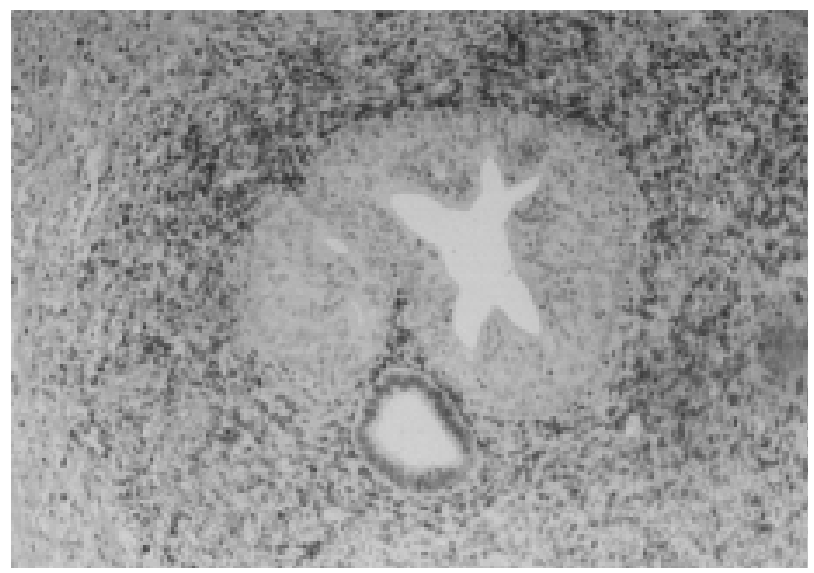

FIGURA 3. Núcleos oscuros positivos para receptores de estrógenos en la glándula inferior endometriósica y negativos en las otras dos glándulas, que corresponden a nidos de Von Brünn con epitelio urotelial. Inmunohistoquimica R.E. 20x.

\section{DISCUSION}

La endometriosis es una enfermedad frecuente que en el $1 \%$ de casos afecta al tracto urinario, siendo el órgano más afectado la vejiga. Se describen dos tipos de endometriosis vesical, una forma primaria, en mujeres sin cirugía ginecológica previa, y una forma secundaria, en mujeres con cirugía pélvica ${ }^{4,5}$, básicamente cesárea, en el $50 \%$ de $\operatorname{casos}^{1,7}$. Aunque la etiología de esta afectación no está clara varias teorías intentan explicar su origen. Así, la teoría embrionaria (restos embrionarios plurivalentes), la metaplásica (origen en el mesotelio celómico) y las inmmunológicas (fallo de inmunidad) han sido barajadas. Sin embargo es la teoría migratoria, ya sea por menstruación retrógrada a través de las trompas, por siembra post-cirugía pélvica o siembra sanguínea o linfática, la teoría más aceptada sobre el origen de la endometriosis urinaria ${ }^{1,2,6,7}$. Este tejido ectópico que de una forma $u$ otra llega a la vejiga, prolifera bajo el efecto de los estrógenos produciendo una reacción inflamatoria local, con fibrosis y cicatrices ${ }^{1}$. Las pacientes refieren síntomas cíclicos premenstruales o catameniales, que incluyen polaquiuria, disuria, imperiosidad y dolor hipogástrico ${ }^{2,3}$, estando las hematurias cíclicas presentes tan sólo en un 30\% de casos ya que las lesiones raramente ulceran la mucosa ${ }^{4,7}$. Grandes lesiones vesicales produciendo efecto masa son raras $^{8}$. Sin embargo, en un $50 \%$ de casos puede palparse masa en el fórnix anterior ${ }^{4,7}$. A pesar de 
esta sintomatología típica, el diagnóstico se alarga en el tiempo 4,5 años ${ }^{7}$. Establecida la sospecha clínica, la ecografía abdominal o transvaginal, la urografía o la TAC pueden aportar nuevos datos $^{2,5,8}$. La cistoscopia permite establecer un diagnóstico en el $65-72 \%$ de casos $^{6}$, como sucedió en el nuestro. En la cistoscopia las lesiones vesicales presentan cambios cíclicos. Son lesiones sólidas con halo edematoso, bullas o quistes azulados, que durante la menstruación aumentan de tamaño y pigmentación ${ }^{3,6}$. La imagen cistoscópica puede confundirse con un tumor vascular $^{8}$ como varicosidades, angiomas, papilomas y úlceras inflamatorias, así como carcinoma infiltrativo o metastásico. La biopsia transuretral nos da el diagnóstico definitivo, aislando glándulas endometriales distendidas por sangre y material necrótico con inflamación y extravasación hemorrágica ${ }^{6,7}$.

Dado que los casos de endometriosis vesical son escasos su tratamiento sigue siendo discutido. El tratamiento de la endometriosis del tracto urinario es básicamente quirúrgico ${ }^{2,6}$, siendo de elección la resección transuretral ${ }^{2}$, sobre todo en las formas intrínsecas que afectan básicamente al detrusor, existiendo alto riesgo de perforación si la resección es completa y de recidivas si es incompleta ${ }^{5}$. Las formas extrínsecas que afectan serosa y peritoneo requieren cistectomía parcial para la extirpación de las lesiones ${ }^{2,7}$. Dada la clara dependencia hormonal de estas lesiones que se demuestra por inmunohistoquímica ${ }^{7}$ la asociación de supresión ovárica se considera fundamental para estas pacientes ${ }^{8}$. El tratamiento definitivo de la endometriosis sería la histerectomía con doble anexectomía, con la consiguiente regresión de las lesiones residuales. Sin embargo, suele asociarse tratamiento hormonal a la cirugía ya sea con anticonceptivos hormonales orales, progestágenos o danazol ${ }^{1,3}$. En la actualidad son los análogos de la GnRH el tratamiento más utilizado, al producir desensibilización hipotalámica, reducción de las gonadotropinas e inhibición la secreción estrogénica ${ }^{6,9}$. La duración del tratamiento debe ser de 6 meses, siendo el efecto indeseable más frecuente la reducción reversible de la masa mineral ósea ${ }^{9}$. Con el tratamiento combinado se consiguen buenos resultados, recidivan- do un $56 \%$ de los casos de endometriosis pélvi$\mathrm{ca}^{7}$. En caso de persistencia o recidiva de los síntomas la resección segmentaria de vejiga está indicada $^{7}$. Se aconseja cistoscopia de control al finalizar el tratamiento, que en nuestro caso fue normal.

Es importante reconocer los síntomas característicos de la endometriosis del tracto urinario para prevenir un innecesario retraso de diagnóstico y de tratamiento que podría desembocar en un aumento de la morbilidad, ya que no debemos olvidar, que no sólo las consecuencias de la obstrucción del tracto urinario o de tratamientos innecesarios suponen un aumento del gasto asistencial, sino que se han descrito casos de transformación maligna de la endometriosis vesical ${ }^{7}$ que deben mantenernos siempre vigilantes ante esta patología.

\section{REFERENCIAS}

1. SCHWARTZWALD D, MOOPPAN UMM, OHM HK, KIM H.: Endometriosis of bladder. Urology 1992; 39: 219-222.

2. LÓPEZ E, PRATS J, PRERA A, COMBALIA N.: Endometriosis vesical simulando un tumor vesical. Arch Esp Urol 1992; 45: 158-160.

3. OJEDA A, RODRÍGUEZ B, ALONSO A, CASTRO AM, BENAVENTE J, BARROS JM, NOGUEIRA JL.: Endometriosis vesical. Actas Urol Esp 1992; 16: 80807.

4. DONNEZ J, SPADA F, SQUIFFLET J, NISOLLE M.: Bladder endometriosis must be considered as bladder adenomyosis. Fertil Steril 2000; 74: 1175-1181.

5. VERCELLINI P, MESCHIA M, DE GIORGI O, PANAZZA S, CORTESI I, CROSIGNANI PG.: Bladder detrusor endometriosis: clinical and pathogenetic implications. J Urol 1996; 155: 770-771.

6. SHOOK TE, NYBERG L.: Endometriosis of the urinary tract. Urology 1988; 31: 1-6.

7. PRICE DT, MALONEY KE, IBRAHIM GK, CUNDIFF GW, LEDER RA, ANDERSON EE.: Vesical endometriosis: report of two cases and review of the literature. Urology 1996; 48: 639-643.

8. TARRAGONA J, DE TORRES I, MOROTE J, LÓPEZPACIOS JL, DE TORRES A.: Arch Esp Urol 1997; 50: 74-76.

9. ROCK JA, MARKHAM SM.: Pathogenesis of endometriosis. Lancet 1992; 340: 1264-1267.

Dr. J. Casasola Chamorro

C/ Santo Toribio de Mogrovejo, 70 - 5ㅇ I

24006 León

(Trabajo recibido el 20 septiembre 2002) 